\title{
Spectral and Cyclic VoltammetricStudies on Cu (II)-Schiff Base Complex Derived from Anthracene-9(10 H)-one
}

\author{
Shaju K S, Joby Thomas K*,Vinod P Raphael, NimmyKuriakose \\ Research Division, Department of Chemistry \\ St. Thomas' College (University of Calicut), Thrissur, Kerala
}

\begin{abstract}
Novel Schiff base chelate of $\mathrm{Cu}(\mathrm{II})$ derived from anthracene-9 (10H)-one with (s)-2-amino-5guanidinopentanoic acid has been synthesized. The ligand and complex were characterized by elemental analysis, molar conductance, magnetic susceptibility and UV,IR, NMR spectroscopic techniques.The redox properties of the ligand and complex were extensively investigated by electrochemical method using cyclic voltammetry $(\mathrm{CV})$. Cyclic voltammetric measurement of $\mathrm{Cu}(\mathrm{II})$ complex display quasireversible redox process due to the $\mathrm{Cu}(\mathrm{II}) / \mathrm{Cu}(\mathrm{I})$ process.
\end{abstract}

Keywords:Schiff base, anthracene-9 (10H)-one,Cyclic Voltammetry

\section{Introduction}

The complexes of Schiff bases with metal ions are very important in the development of coordination chemistry. These complexes are also known to have anticorrosion properties and biological activities such as antimicrobial, antifungal, and antitumor [1-17]. Copper complexes have played a seminal role in the development of modern coordination chemistry, but also they can also be found at key points in the development of inorganic biochemistry, catalysis and optical materials [18]. In the present paper we report the synthesis and characterization of $\mathrm{Cu}$ (II) complex of Schiff base derived from the condensation of anthracene-9 (10H)-one with (s)-2-amino-5-guanidinopentanoic acid.

\section{Materials and Methods}

\section{Experimental}

All the chemicals used were of analytical grade and solvents used for spectral studies were of spectroscopic grade.Carbon, hydrogen,and nitrogen content of the ligand and itsCu(II) metal complex were determined by microanalysis using Elementar make Vario EL III model CHN analyzer. Molar conductance of the complex at room temperature was measured using a ELICO conductivity meter. Magnetic susceptibility was measured by Sherwood, UK (Mark 1) balance. The UV-visible spectra of the ligand and complex were recorded on a Shimadzu UV-visible-1800 Spectrophotometer using DMSO as solvent. The infrared spectra of the ligand and metal complex were recorded using $\mathrm{KBr}$ disc technique in the range $4000-400 \mathrm{~cm}^{-1}$ on a Shimadzu model FT-IR Spectrometer (Model IR affinity). ${ }^{1} \mathrm{H}$ NMR and ${ }^{13} \mathrm{C}$ NMR spectra were recorded at 300 and $75 \mathrm{MHz}$, respectively, in DMSO- $\mathrm{d}_{6}$ for all compounds on a Bruker AMX-400 NMR spectrometer. The cyclic voltammetry studies were carried out in an Iviumcompactstat-e electrochemical system with three electrode assemblies which were connected to a personal computer assisted with software "Ivium soft". The three electrode system consisted of glassy carbon (working), platinum wire (counter) and $\mathrm{Ag} / \mathrm{AgCl}$ (reference) electrodes.

\section{Synthesis of Schiff base ligand}

Polynuclear Schiff base (s)-2-(anthracene-9(10H)-ylideneamino)-5-guanidinopentanoic acid (A9Y5GPA) was obtained by the condensation of equimolar mixture of anthracene-9 (10H)-one and (s)-2amino-5-guanidinopentanoic acid in ethanol. The reaction mixture was refluxed for 5 hours, cooled by keeping overnight to obtain dark coloured compound, filtered, washed and dried.

\section{Synthesis of $\mathrm{Cu}(\mathrm{II})$ Schiff base complex}

The hot ethanolic solution of anthracene-9(10H)-one (1mM), and (s)-2-amino-5-guanidinopentanoic acid $(1 \mathrm{mM})$ were refluxed for $2 \mathrm{hr}$. To this added cupric acetate $(1 \mathrm{mM})$ and refluxed for about $6-7$ hours in the presence of sodium acetate $(1.0 \mathrm{~g})$. The solution was concentrated, cooled at room temperature for overnight and filtered. The metal complex was dried in a desiccator over anhydrous calcium chloride.

\section{Results And Discussion}

The analytical data along with some physical properties of the Schiff base and complex are summarized in Table 1. Theanalytical data show that the metal to ligand ratio is $1: 1$. The complex is 
colouredand non hygroscopic in nature. It is insoluble in water but slightly soluble in organic solvents like ethanol, methanol and DMSO. The very low molar conductance value of the complex in DMSO at a concentration of $10^{-3} \mathrm{M}$ at room temperature was indicative of their non electrolytic nature. The $\mathrm{Cu}$ (II) chelate exhibited the magnetic moment 1.38B.M which is a low value compared to the spin only value 1.73B.M. This suggests a dimeric square planar configuration facilitating anti-ferromagnetic exchange.

\section{Electronic spectra}

The electronic spectrum of the Schiff base A9Y5GPA showed three specific bands around 26400, 33200 and $40616 \mathrm{~cm}^{-1}$, characteristic of $\mathrm{n} \rightarrow \pi^{*}, \pi \rightarrow \pi^{*}$ and $\mathrm{n} \rightarrow \sigma^{*}$ transitions respectively. Electronic spectrum of the $\mathrm{Cu}$ (II) chelate gave a single broad and poorly resolved absorption band around $13880 \mathrm{~cm}^{-1}$, characteristic of $\mathrm{Cu}(\mathrm{II})$ with $\mathrm{D}_{4 \mathrm{~h}}$ symmetry.

Table 1.Microanalytical data of Schiff base and its $\mathrm{Cu}(\mathrm{II})$ complex

\begin{tabular}{|c|c|c|c|c|c|c|c|c|}
\hline & & Yield & Mol.w & \multirow{2}{*}{$\begin{array}{c}\text { M.P } \\
(\%)\end{array}$} & $\mathrm{t}$ & $\begin{array}{c}\text { Metal \% Found } \\
\left({ }^{0} \mathrm{C}\right)\end{array}$ & \multicolumn{3}{|c|}{$\begin{array}{c}\text { Elemental Analysis } \\
\text { (Calculated) }\end{array}$} & \multicolumn{3}{|c|}{ Found (Calculated) } \\
\cline { 5 - 9 } & Colour & & & & & & $\mathrm{H} \%$ & $\mathrm{~N} \%$ \\
\hline A9Y5GPA & Dark & 85 & 265 & 235 & & $\begin{array}{c}68.18 \\
(68.48)\end{array}$ & $\begin{array}{c}6.03 \\
(6.27)\end{array}$ & $\begin{array}{c}15.48 \\
(15.97)\end{array}$ \\
\hline$[\text { CuLAc }]_{2}$ & $\begin{array}{c}\text { Bluish } \\
\text { Green }\end{array}$ & 72 & 944 & $>300$ & $\begin{array}{c}6.44 \\
(6.73)\end{array}$ & $\begin{array}{c}55.62 \\
(55.94)\end{array}$ & $\begin{array}{c}4.88 \\
(5.09)\end{array}$ & $\begin{array}{c}11.26 \\
(11.86)\end{array}$ \\
\hline
\end{tabular}

\section{IR Spectra}

The stretching vibration of $\mathrm{NH}_{2}$ and $\mathrm{NH}$ group of the ligand appeared in the region $3425 \mathrm{~cm}^{-1}$ and $3304 \mathrm{~cm}^{-1}$ respectively. The asymmetric and symmetric stretching frequencies of the carboxylate groups exhibited respectively at $1656 \mathrm{~cm}^{-1}$ and $1456 \mathrm{~cm}^{-1}$. The IR spectral data of the ligand A9Y5GPA contain a significant absorption frequency at $1595 \mathrm{~cm}^{-1}$ which may be assigned to the stretching frequency of $\mathrm{C}=\mathrm{N}$ group which upon complexation undergoes red shift by ca. $30 \mathrm{~cm}^{-1}$ indicating the involvement of azomethine nitrogen in coordination.The asymmetric and symmetric stretching vibrations of $\mathrm{COO}^{-}$of ligand shifted to lower frequency upon complexation and were appeared at $\approx 1650 \mathrm{~cm}^{-1}$ and $\approx 1430 \mathrm{~cm}^{-1}$. The $\Delta v$ value $\left(v_{\mathrm{COO}}^{-}(\operatorname{asym})^{-} v_{\mathrm{COO}}^{-}\right.$ $(\mathrm{sym}) \approx 220 \mathrm{~cm}^{-1}$ are consistent with monodentate carboxylate moiety. Conclusive evidence of bonding of the ligand to the central metal ion is provided by the appearance of bands at the region $520-552 \mathrm{~cm}^{-1}$ and 442 $467 \mathrm{~cm}^{-1}$, which can be assigned to $v_{\mathrm{M}-\mathrm{O}}$ and $v_{\mathrm{M}-\mathrm{N}}$ bands respectively.

\section{${ }^{1} \mathrm{H}$ NMR and ${ }^{13} \mathrm{C}$ NMR Spectra}

The ${ }^{1} \mathrm{H}$ NMR spectrum of the ligand showed a singlet peak at highly deshielded region $(\delta 12.2)$ can be assigned to the carboxylic acid proton. All aromatic protons showed their characteristic resonance peaks between $\delta 7.40$ and 8.35 in the ${ }^{1} \mathrm{H}$ NMR spectrum. A broad peak at $\delta 6.97$ can be attributed to free $\mathrm{NH}_{2}$ proton in the ligand. The methylene proton attached to NH group showed a peak at $\delta 2.45$. The $\mathrm{CH}$ proton attached to $\mathrm{N}=\mathrm{C}<$ (azomethine) exhibited a peak at $\delta 4.46$. The ${ }^{13} \mathrm{C}$ NMR spectrum of the ligand exhibited a peak at 182.1 ppm due to the presence of highly electron withdrawing oxygen atoms on the carboxylic group and also due to the $\pi$-electron anisotropic effect. The methylene carbon attached to NH group showed a peak at $\delta 37.66 \mathrm{ppm}$. The carbon atom of the azomethine moiety resonated at $140.05 \mathrm{ppm}$. The proton $\mathrm{nmr}$ spectrum of the complex was very much complex and peak detection was difficult with respect to each characteristic protons. The NMR spectrum of the complex exhibited significant difference from the spectrum of the ligand A9Y5GPA mainly in two regions. The disappearance of the signal at $\delta 12.2$ due to the acid proton in the ligand, is a clear indication of the coordination of the ligand through the carboxylate group. Similarly, there is a downward shift of the signals due to carboxylic acid and azomethine carbon atoms. This can be attributed to the lowering of electron densities as a result of coordination to the metal ion. The spectral and elemental analysis confirms the general structures of the ligand and complex as shown in Fig.1 and Fig.2 respectively.

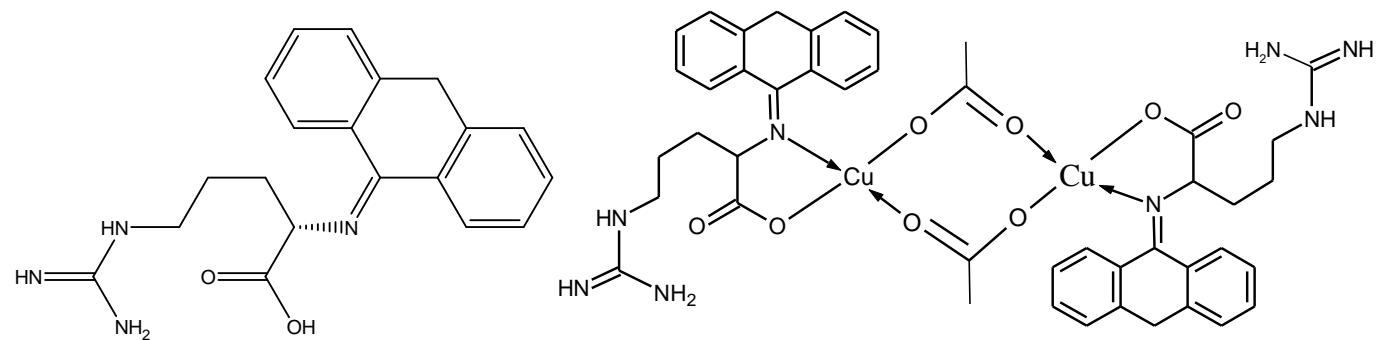

Fig. 1.Structure of Schiff base A9Y5GPA

Fig. 2.Structure of $\mathrm{Cu}(\mathrm{II})$ - A9Y5GPA complex 


\section{CV studies on the Schiff base A9Y5GPA}

The electrochemical response of the Schiff base A9Y5GPA was studied by recording the cyclic voltammogram in the potential range $+1.0 \mathrm{~V}$ to $-1.0 \mathrm{~V}$. The Fig. 3 shows the CV of A9Y5GPA at a scan rate of $0.1 \mathrm{~V} / \mathrm{s}$. It can be observed that there are one cathodic peak represented by A and three anodic peaks represented by $B, C$ and $D$. The $E_{p}$ and $i_{p}$ values of the various peaks are listed in the table 4.2. From the Fig. 3 and Table 2, the electrochemical characteristic of A9Y5GPA can be interpreted as follows.

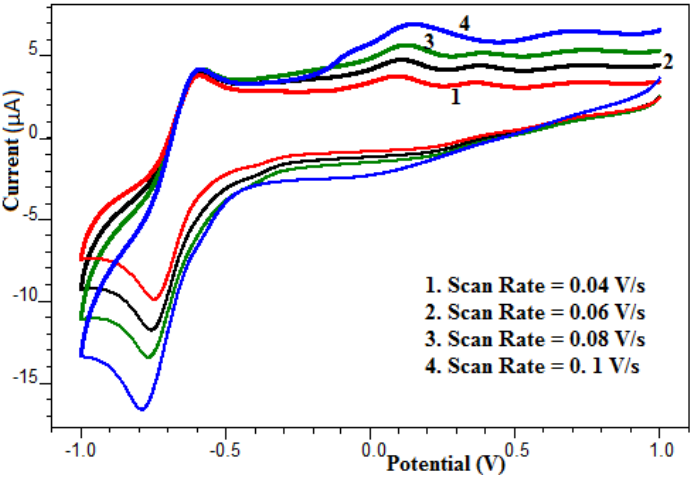

Fig. 3.Cyclic Voltammogram of A9Y5GPA at a scan rate of $0.1 \mathrm{~V} / \mathrm{s}$

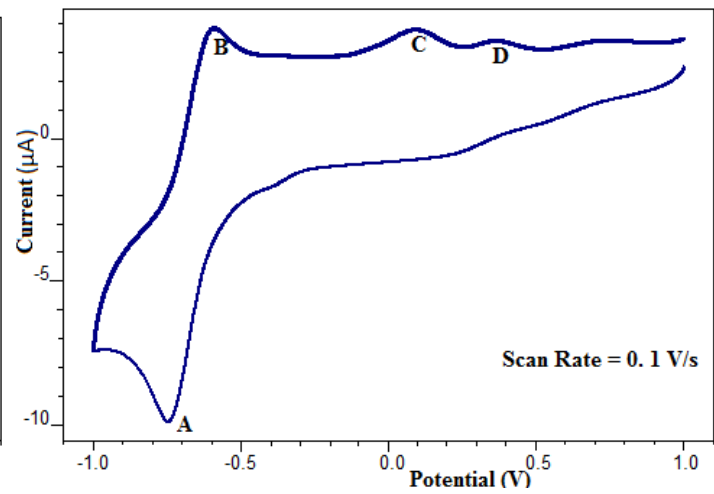

Fig. 4. Cyclic Voltammogram of A9Y5GPA at scan rates $0.04-0.1 \mathrm{~V} / \mathrm{s}$

The peak A appeared at $-0.790 \mathrm{~V}$ can be considered due to the two electron reduction process of the azomethine moiety into saturated system. The involvement of two electrons was assumed, since the height of this cathodic peak was significantly higher than the other normal peaks. The two oxidation peaks observed at B and $\mathrm{C}$ can be attributed to the two successive oxidation processes of the reduced form of the Schiff base. Thus the original molecule regenerates at a higher oxidation potential $0.390 \mathrm{~V}$. The overall mechanism of the redox process is depicted in the Fig. 5. The third oxidation peak D appeared at $0.142 \mathrm{~V}$ in the volammogram may be due to the involvement of (s)-2-amino-5-guanidinopentanoic acid moiety.

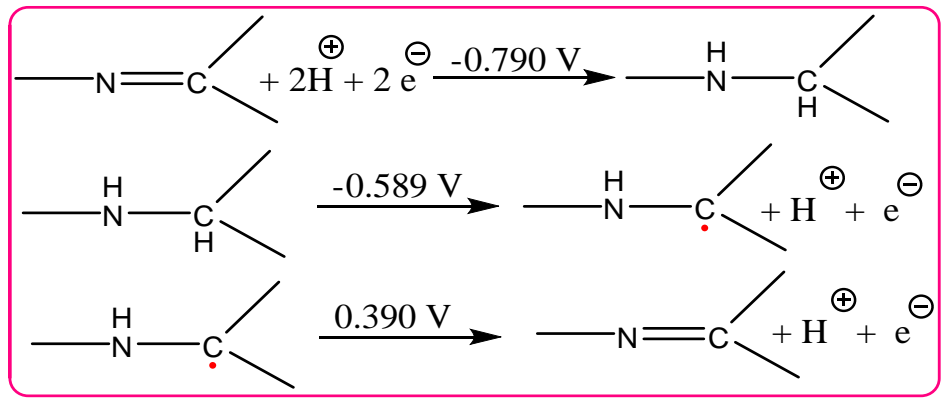

Fig. 5.Mechanism of redox process at azomethine moiety of A9Y5GPA

Table 2. Cyclic Votammetric data for Schiff base A9Y5GPA

\begin{tabular}{|c|c|c|c|c|c|}
\hline $\begin{array}{c}\text { Scan Rate } \\
(\mathrm{V} / \mathrm{s})\end{array}$ & Redox Peak & $\mathrm{E}_{\mathrm{pa}}(\mathrm{V})$ & $E_{p c}(V)$ & $i_{p a}(\mu \mathrm{A})$ & $i_{p c}(\mu \mathrm{A})$ \\
\hline \multirow{4}{*}{0.04} & A & - & -0.747 & - & 5.03 \\
\hline & $\mathrm{B}$ & -0.589 & & 3.105 & \\
\hline & $\mathrm{C}$ & 0.083 & - & 0.569 & - \\
\hline & $\mathrm{D}$ & 0.362 & - & 0.246 & - \\
\hline \multirow{4}{*}{0.06} & A & - & -0.758 & - & 5.382 \\
\hline & B & -0.588 & & 3.30 & \\
\hline & $\mathrm{C}$ & 0.110 & - & 0.609 & - \\
\hline & $\mathrm{D}$ & 0.374 & - & 0.285 & - \\
\hline \multirow{4}{*}{0.08} & $\mathrm{~A}$ & - & -0.766 & - & 5.75 \\
\hline & $\mathrm{B}$ & -0.585 & & 4.172 & \\
\hline & $\mathrm{C}$ & 0.120 & - & 0.871 & - \\
\hline & $\mathrm{D}$ & 0.388 & - & 0.197 & - \\
\hline \multirow{4}{*}{0.10} & $\mathrm{~A}$ & - & -0.790 & - & 7.08 \\
\hline & $\mathrm{B}$ & -0.589 & - & 4.66 & - \\
\hline & $\mathrm{C}$ & 0.142 & - & 0.990 & - \\
\hline & $\mathrm{D}$ & 0.390 & - & 0.394 & - \\
\hline
\end{tabular}




\section{CV studies on the Cu(II)-A9Y5GPA complex}

Fig. 6 and 7 show the cyclic voltammogram of $\mathrm{Cu}(\mathrm{II})$ complex at a scan rate of $0.1 \mathrm{~V} / \mathrm{s}$ and $0.04-0.1$ $\mathrm{V} / \mathrm{s}$ respectively. The Table 3 exhibits the $\mathrm{CV}$ data of $\mathrm{Cu}(\mathrm{II})$ complex at different scan rates.

Table3. Cyclic Votammetric data for $\mathrm{Cu}(\mathrm{II})$ - A9Y5GPA complex

\begin{tabular}{|c|c|c|c|c|c|c|}
\hline $\begin{array}{c}\text { Scan } \\
\text { Rate } \\
(\mathrm{V} / \mathrm{s})\end{array}$ & $\begin{array}{c}\mathrm{E}_{\mathrm{pa}} \\
(\mathrm{V})\end{array}$ & $\begin{array}{c}\mathrm{E}_{\mathrm{pc}} \\
(\mathrm{V})\end{array}$ & $\Delta \mathrm{E}_{\mathrm{p}}$ & $\begin{array}{c}\mathrm{i}_{\mathrm{pa}} \\
(\mu \mathrm{A})\end{array}$ & $\begin{array}{c}\mathrm{i}_{\mathrm{pc}} \\
(\mu \mathrm{A})\end{array}$ & $\mathrm{i}_{\mathrm{pa}} / \mathrm{i}_{\mathrm{pc}}$ \\
\hline 0.04 & -0.507 & -0.671 & 164 & 0.608 & 2.687 & 0.2 \\
\hline 0.06 & -0.511 & -0.685 & 174 & 0.675 & 3.382 & 0.2 \\
\hline 0.08 & -0.526 & -0.693 & 167 & 0.771 & 3.838 & 0.2 \\
\hline 0.1 & -0.528 & -0.712 & 184 & 0.783 & 4.605 & 0.2 \\
\hline
\end{tabular}

The cyclic voltammogram of $\mathrm{Cu}(\mathrm{II})$ complex $(+1.0 \mathrm{~V}$ to $-1.0 \mathrm{~V})$ at a scan rate of $0.1 \mathrm{~V} / \mathrm{s}$ shows a quasireversible peak in the negative region, characteristic of the $\mathrm{Cu}(\mathrm{II}) \rightarrow \mathrm{Cu}(\mathrm{I})$ couple at $\mathrm{E}_{\mathrm{pc}}=-0.712$, with associated anodic peak at $\mathrm{E}_{\mathrm{pa}}=-0.528$ for $\mathrm{Cu}(\mathrm{I}) \rightarrow \mathrm{Cu}$ (II). On comparing the voltammogram of A9Y5GPA and its $\mathrm{Cu}$ (II) complex, it is evident that the oxidation peaks appeared in the voltammogram of Schiff base (peaks $\mathrm{C}$ and $\mathrm{D}$ ) was totally disappeared on complexation. The peak separation value also increases with the scan rate, giving further evidence for the quasi-reversible $\mathrm{Cu}(\mathrm{II}) / \mathrm{Cu}(\mathrm{I})$ couple.

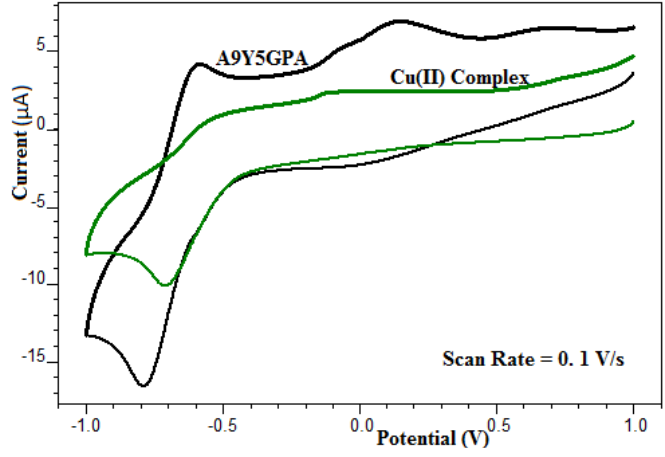

Fig. 6. Cyclic Voltammogram of A9Y5GPA and $\mathrm{Cu}(\mathrm{II})$ complex at a scan rate of $0.1 \mathrm{~V} / \mathrm{s}$

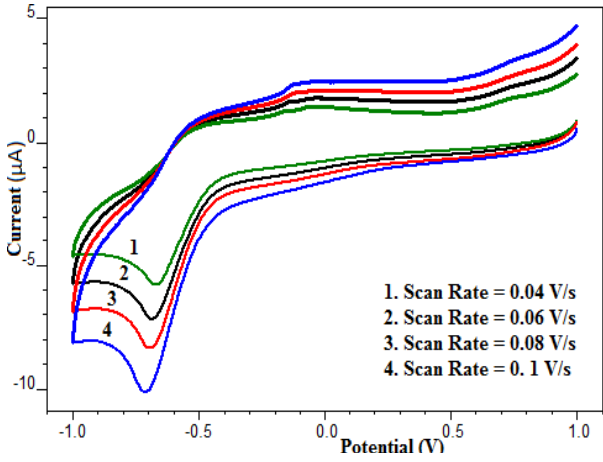

Fig. 7.Cyclic Voltammogram of $\mathrm{Cu}(\mathrm{II})$ A9Y5GPA complex atscan rates $0.04-0.1 \mathrm{~V} / \mathrm{s}$

\section{Effect of scan rate and multiple scan on the voltammogram of A9Y5GPA and Cu(II) complex}

Fig.4shows the cyclic voltammogram of A9Y5GPA at different scan rate. As the scan rate increases, the $\mathrm{E}_{\mathrm{pc}}$ values are shifted to more negative potentials. For the peaks B, C and D, no counter cathodic peak was observed in the voltammogram. Similarly counter anodic peak was absent for the reduction process designated by ' $A$ ' and it may be concluded that the reduction and oxidation process occurred in the potential range -1 to $+1 \mathrm{~V}$ for the Schiff base A9Y5GPA were irreversible in nature.

The variation of $i_{p}$ values with the square root of scan rate is depicted in the Fig.8 and 9. The currentscan responses $[19,20]$ ( $i_{p}$ versus $v^{1 / 2}$, Randles-Sevcik representation) are straight lines which exhibit slight deviations from linearity. These deviations suggest a change from a diffusion-controlled process to a mixed controll process.

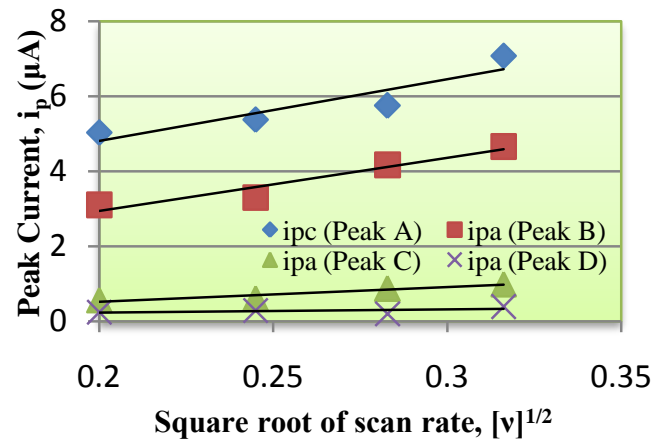

Fig. 8.Plot of peak current againstsquare root of scan rate of A9Y5GPA

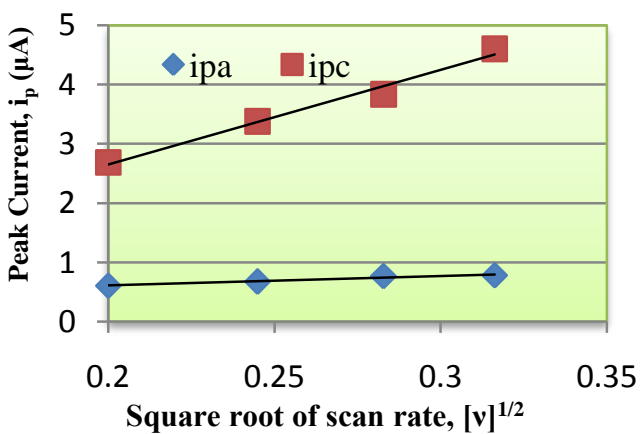

Fig. 9.Plot of peak current against square root of scan rateof $\mathrm{Cu}(\mathrm{II})-\mathrm{A} 9$ Y5GPA complex 
Fig.10 and 11represent CV recorded at a scan rate of $0.1 \mathrm{~V} / \mathrm{s}$ with 5 scan cycles of the ligand and complex respectively. Since all the peaks were appeared in the same position in all the cycles, it is concluded that there is no adsorption of the compound on the glassy carbon electrode surface.

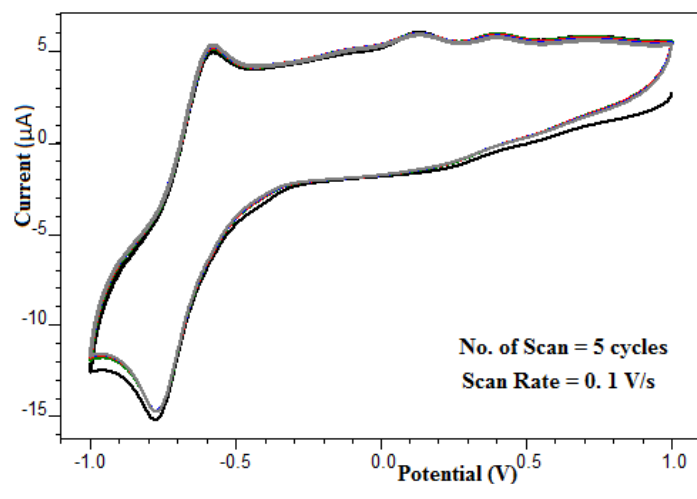

Fig. 10.Cyclic Voltammogram of Schiff base A9Y5GPAwith multiple scan cycles

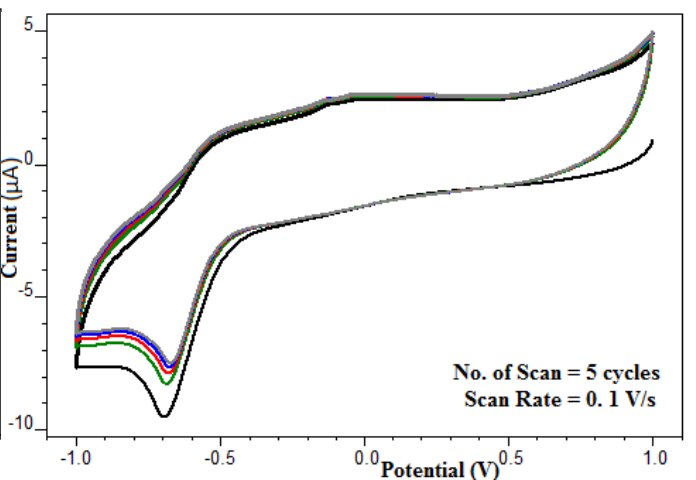

Fig. 11.Cyclic Voltammogram of Cu(II)-A9Y5GPA complex with multiple scan cycles

\section{Conclusion}

In the present work, complex of $\mathrm{Cu}$ (II) with Schiff base derived from anthracene-9 (10H)-one and (s)2-amino-5-guanidinopentanoic acid was synthesized and characterised. The Schiff base act as a monovalent bidentate ligand. On the basis of different micro analytical and spectra analytical techniques, the structures of the ligand and complex are proposed. The electrochemical properties of the $\mathrm{Cu}(\mathrm{II})$ complex revealed the quasireversible one electron transfer redox process.

\section{Reference}

[1]. P. K. Panchal, P. B. Pansuriya, and M. N. Patel, Study on increase in toxicity of Schiff bases on microorganism on chelation with metal, Toxicological and Environmental Chemistry, 88(1),2006, 57-64.

[2]. K.S.Shaju,K.J.Thomas, V.P.Raphael andA.Paul,Synergisticeffect of KI on corrosion inhibition of mild steel by polynuclearschiff base in sulphuric acid, ISRN Corrosion,2012,doi:10.5402/2012/425878.

[3]. M. Tümer, E. Akgün, S. Toroglu, A. Kayraldız, and L. Dönbak, Synthesis and characterization of Schiff base metal complexes: their antimicrobial, genotoxicity and electrochemical properties, Journal of Coordination Chemistry, 61(18), 2008, $2935-2949$.

[4]. A. Gölcü, M. Tümer, H. Demirelli, and R. A. Wheatley, $\mathrm{Cd}(\mathrm{II})$ and $\mathrm{Cu}(\mathrm{II})$ complexes of polydentate Schiff base ligands: synthesis, characterization, properties and biological activity, InorganicaChimicaActa, 358(6), 2005,1785-1797.

[5]. M. Tümer, N. Deligonul, and A. Gölcü, Mixed-ligand copper(II) complexes: investigation of their spectroscopic, catalysis, antimicrobial and potentiometric properties, Transition Metal Chemistry, 31(1), 2006, 1-12.

[6]. M. Arif, M. M. R. Qurashi, and M. A. Shad, Metal-based antibacterial agents: synthesis, characterization, and in vitro biological evaluation of cefixime-derived Schiff bases and their complexes with $\mathrm{Zn}(\mathrm{II}), \mathrm{Cu}(\mathrm{II}), \mathrm{Ni}(\mathrm{II})$, and $\mathrm{Co}(\mathrm{II})$, Journal of Coordination Chemistry, 64(11), 2011, 1914-1930

[7]. K.S.Shaju,K. J.Thomas and V. P.Raphael, Effect of iodide on the corrosion inhibitive behaviour on carbon steel by an azomethine compound derived from anthracene-9(10 H)-one, Oriental Journal of Chemistry, 30(2), 2014, 807-813.

[8]. M. M. Aboaly and M. M. H. Khalil, Synthesis and spectroscopic study of $\mathrm{Cu}(\mathrm{II})$, $\mathrm{Ni}(\mathrm{II})$, and $\mathrm{Co}(\mathrm{II})$ complexes of the ligand salicylidene-2amino thiophenol, Spectroscopy Letters, 34(4), 2001, 498-504.

[9]. Y. T. Li, C. W. Yan, and X. C. Zeng, Heterobinuclear copper(II)-lanthanoid(III) complexes bridged by N,N'oxamidobis(benzoato)cuprate(II), Transition Metal Chemistry, 26(1-2), 2001,110-115.

[10]. K. A. R. Salib, A. A. Saleh, S. Abu El-Wafa, and H. F. O. El-Shafiy, Preparation and characterization of novel asymmetrical Schiff-base ligands derived from 2-methyl-7-formyl-8-hydroxyquinoline and their metal complexes, Journal of Coordination Chemistry, 56(4), 2003.

[11]. H. Chakraborty, N. Paul, M. L. Rahman, Catalytic activities of Schiff bases aquo complex of Cu(II) in the hydrolysis of amino acid esters, Transition Metal Chemistry, 19, 1994, 524-526.

[12]. K. S. Shaju, K. J. Thomas, V. P. Raphael, and A. Paul, Electrochemical and surface morphological studies of carbon steel corrosion by a novel polynuclear Schiff base in HCl Solution, ISRN Electrochemistry, 2013,dx.doi.org/10.1155/2013/820548.

[13]. T. D. Bharamagouclar, M.A. Pujar, A.R. Alagawadi, Biological activity of Schiff base and their metal complexes, Current Science, 56,1987, 889-890.

[14]. B. Kołodziej,E. Grech,W. Schilf,B. Kamieński, A. Pazio and K. Woźniak, The NMR and X-ray study of L-arginine derived Schiff bases and its cadmium complexes, Journal of Molecular Structure, 1063(24), 2014, 145-152.

[15]. Z. H. Chohan and C. T. Supuran, Structure and biological properties of first row d-transition metal complexes with N-substituted sulfonamides, Journal of Enzyme Inhibition and Medicinal Chemistry, 23(2), 2008, 240

[16]. M. Arif, M. M. R. Qurashi, M. A. Shad, Metal-based antibacterial agents: synthesis, characterization, and in vitro biological evaluation of cefixime-derived Schiff bases and their complexes with $\mathrm{Zn}(\mathrm{II}), \mathrm{Cu}(\mathrm{II}), \mathrm{Ni}(\mathrm{II})$, and $\mathrm{Co}(\mathrm{II})$, Journal of Coordination. Chemistry, 64(11), 2011, 1914

[17]. J.Thomas and G. Parameswaran, Anti tumour and thermo gravimetric studies of transition metal complexes of the Schiff base, anthracene-9carboxaldehyde thiosemicarbazone, AsianJournal of Chemistry, 14(3-4), 2002,1370-1382.

[18]. R. Katwal, H. Kaur, B. K. Kapur,Applications of Copper-Schiff base complexes: A review, Scientific Reviews and chemical communications,3(1), 2013, 1-15.

[19]. A.D. Kulkarni, S.A.Patil and P.S. Badami, Electrochemical properties of some transition metal complexes: Synthesis, characterization and in-vitro antimicrobial studies of $\mathrm{Co}(\mathrm{II}), \mathrm{Ni}(\mathrm{II}), \mathrm{Cu}(\mathrm{II}), \mathrm{Mn}(\mathrm{II})$ and $\mathrm{Fe}(\mathrm{III})$ complexes, International Journal of Electrochemical Science,4,2009,717-729.

[20]. S. Zolezzi, E. Spodine and A. Decinti, Electrochemical studies of Cu(II) complexes with Schiff base ligands, Polyhedron, 21, 2002, 55. 